\title{
Sertraline Measurement
}

National Cancer Institute

\section{Source}

National Cancer Institute. Sertraline Measurement. NCI Thesaurus. Code C147432.

The determination of the amount of sertraline present in a sample. 